\title{
Avaliação da Perda de Massa de Revestimento Duro Depositado por Soldagem com Arame Tubular de Liga FeCrC-Ti
}

\author{
(Evaluation of Mass Loss of Weld-Deposited Hardfacing with Cored Wire Ti-FeCrC Alloy)
}

\author{
Fernando Henrique Gruber Colaço ${ }^{1,2}$, Ossimar Maranho ${ }^{1}$ \\ ${ }^{1}$ Universidade Tecnológica Federal do Paraná - PPGEM, Curitiba, Paraná, Brasil. fernandogruber@ifsc.edu.br, maranho@utfpr. \\ edu.br \\ ${ }^{2}$ Instituto Federal de Santa Catarina, Jaraguá do Sul - Santa Catarina, Brasil.
}

\begin{abstract}
Resumo
Neste trabalho estudou-se a perda de massa de revestimento duro aplicado pelo processo de soldagem com arame tubular com a variação de energia de soldagem, gás de proteção e número de camadas do revestimento. Com arame tubular autoprotegido de liga $\mathrm{Fe}$-Cr-C-Ti foram depositados cordões sobrepostos na formação de camadas de revestimento sobre chapas de aço ao Carbono AISI 1020 para a análise da perda de massa, dureza, microestrutura. Foram realizadas medições de dureza na superfície dos corpos de prova de desgaste. Abrasômetro tipo roda de borracha foi usado para determinar a perda de massa dos revestimentos. Os revestimentos apresentaram microestrutura martensítica e austenita retida com carbonetos finamente dispersos na matriz. Os principais fatores que contribuíram para o aumento na perda de massa foram as trincas devido a maior taxa de resfriamento das amostras depositadas com baixa energia de soldagem, a diluição na primeira camada de todas as amostras também contribuiu para o aumento na perda de massa. As menores perdas de massa foram dos revestimentos de duas e quatro camadas depositados com alta energia de soldagem. A fração volumétrica de carbonetos de Titânio contribuiu para a diminuição do caminho livre médio entre as partículas de carbonetos aumentando a resistência ao desgaste dos revestimentos.
\end{abstract}

Palavras-chave: FCAW, carbonetos de Titânio, desgaste abrasivo.

Abstract: In this papper, have been studied the mass loss of hardfacing applied by flux cored arc welding. Heat input, shielding gás and number of layers coating were changed to application of Fe-Cr-Ti-C self-shielded tubular wire. Beads overlapped were deposited on plates of carbon steel AISI 1020 to analyze the mass loss, hardness and microstructure. For the analysis of mass loss were deposited beads forming overlapped layers coatings. Hardness measurements were performed on the surface of the specimens of wear. Rubber wheel abrasion tester was used to access the mass loss of coatings. The coatings had retained austenite and martensite microstructure with carbides finely dispersed in the matrix. The main factors that contributed to the increase in mass loss were the cracks due to higher cooling rate of the samples deposited with low heat input, the dilution in the first layer of all samples also contributed to the increase in mass loss. The smallest mass losses were those deposited coatings with high heat input the second and fourth layer, the samples AC2, AC4 and AS2. The volume fraction of titanium carbides contributed to the decrease in the mean free path between the particles of carbides increase the wear resistance of the coatings.

Key-words: FCAW, carbides of titanium, abrasive wear.

\section{Introdução}

Aumentar o tempo de vida dos componentes mecânicos é de grande interesse na indústria, principalmente quando se fala em desgaste abrasivo. $\mathrm{O}$ desgaste abrasivo tem como consequência a perda de massa, que causa mudanças de dimensões e leva a falha dos componentes mecânicos [1]. Isso está ligado ao custo de reposição das peças devido a onerosidade dos materiais e as

Recebido em 10/12/2013, texto final em 08/04/2014. paradas da produção [2].

Alguns métodos foram desenvolvidos e incorporados aos processos de fabricação visando prolongar a durabilidade de componentes [3]. Entre eles, as técnicas de endurecimento superficial ou hardfacing, que trata da deposição por soldagem de um material com elevada resistência ao desgaste sobre a superfície da peça $[1,4]$.

Em face de grande demanda por componentes com alto desempenho em relação ao desgaste abrasivo é preponderante a utilização de processos de fabricação que proporcionem a obtenção dos mesmos com menor relação custo/beneficio. Como, por exemplo, a aplicação de revestimentos com maior dureza em relação ao material base utilizando processos de soldagem. 
Nesse sentido, procura-se fabricar componentes bimetálicos, ou seja, com núcleo constituído de materiais mais dúcteis e menos resistentes ao desgaste revestido por um material duro [2].

Os processos de soldagem mais utilizados para a aplicação de revestimentos são aqueles que têm como característica grande taxa de deposição e, se possível, menor diluição. Com isso obtém-se alto rendimento e menor influência do material base na composição do metal solidificado [5].

Dentre os processos, um dos quais se enquadra no quesito de produtividade, é o processo de soldagem com arame tubular (FCAW - Flux Cored Arc Welding) [6,7]. LIMA e FERRARESI [8] estudaram a aplicação de revestimentos duros depositados por soldagem com arames tubulares em facas picadoras de canade-açúcar. Utilizaram quatro tipos de consumíveis, sendo três arames tubulares e um eletrodo revestido com elementos básicos idênticos de $\mathrm{FeCrC}$, diferenciados pela adição de Ti e $\mathrm{Nb}$.

Por outro lado BUCHELY et al. [9] avaliaram revestimentos de várias ligas contendo Ferro, Cromo, Carbono e outros elementos depositados pelo processo eletrodo revestido. Constataram que a liga rica em $\mathrm{Cr}$ (liga do Tipo $\mathrm{FeCrC}$ ) demonstrou maior resistência ao desgaste abrasivo utilizando Abrasômetro Roda de Borracha que a liga rica em carbonetos complexos, como $\mathrm{Mo}_{2} \mathrm{C}, \mathrm{NbC} \mathrm{e}_{7} \mathrm{C}_{3}$ (liga C-Cr-W-Nb-Mo-V). A vantagem da técnica de soldagem com arame tubular está na obtenção de componentes com adequada resistência ao desgaste utilizando quantidade menor de materiais onerosos. Além disso, esses componentes, também, podem ser recuperados várias vezes sem que ocorra a perda por danos nas suas dimensões, pois com o desgaste da superfície é possível a aplicação de novo revestimento duro.

Especificamente, no caso do desgaste abrasivo, é interessante que os materiais possuam carbonetos duros inseridos em uma matriz dúctil $[10,11]$. Uma possibilidade de obtenção de carbonetos é quando da solidificação de materiais com altos teores de Carbono e de elementos formadores de carbonetos como Vanádio, Molibdênio, Tungstênio e Titânio Os carbonetos podem ser obtidos pelo controle das variáveis de processo que proporcionam a solidificação em condições tais que favoreçam a formação de carbonetos duros em uma matriz dúctil [12,13]. Nesses casos os revestimentos podem ser aplicados por processos de soldagem, nos quais também ocorre a fusão do material base $[14,15]$.

Um dos fatores que influenciam sobre a fração volumétrica dos carbonetos formado no revestimento é a diluição. A diluição do material base no revestimento é responsável pela perda de dureza e possivelmente aumento no desgaste. RIBEIRO et al. [16] verificaram maior perda de volume nos pontos que registraram maior diluição. De forma geral uma maior diluição tem influência negativa na resistência ao desgaste por abrasão. Este resultado é explicado pela relação que existe entre a diluição e a composição química do metal depositado e consequentemente com a microestrutura final do revestimento.

Além da diluição é possível que a atmosfera protetora também tenha influência na formação de carbonetos. Estudo realizado por CARDOSO et al. [17], mostrou que na aplicação de revestimentos com arame tubular ocorre aumento do teor de Carbono no metal de solda com a variação do tipo de gás de proteção. Nesse caso, foi utilizado arame e metal base de ligas de Ni-Cr, que são constituídos de menor número de elementos de liga com afinidade para formar carbonetos. Por outro lado, existem arames tubulares fornecidos por vários fabricantes que possuem em sua composição química maior quantidade de elementos formadores de carbonetos, similar aos aços rápidos.

Diante disso, neste trabalho foram caracterizadas as propriedades do material depositado na formação de revestimentos variando fatores como a energia de soldagem, o gás de proteção e o número de camadas. Este trabalho tem por objetivo principal determinar a perda de massa de revestimentos duros aplicados pelo processo de soldagem com arame tubular autoprotegido usando uma liga do sistema Fe-Cr-C-Ti. Para alcançar esse objetivo foi determinada a influência da energia de soldagem, o CO2 como gás de proteção adicional e o número de camadas na dureza, na microestrutura e na perda de massa dos revestimentos; e os mecanismos de desgaste na superfície dos revestimentos.

\section{Matérias e Métodos}

Foi utilizada uma fonte de soldagem eletrônica multiprocesso ajustada para soldar no modo de tensão constante, denominada INVERSAL 450. Os cordões de solda para a formação das amostras de revestimentos foram depositados em chapas de aço Carbono AISI 1020 utilizando temperatura ambiente $\left(25^{\circ} \mathrm{C}\right)$ entre passes. As chapas foram utilizadas nas dimensões de $6,5 \mathrm{~mm}$ de espessura, largura 100 mm e comprimento $200 \mathrm{~mm}$, e um sistema de deslocamento automático da tocha de soldagem, denominado TARTÍLOPE V1 para a deposição controlada dos cordões. Foi utilizado um sistema de aquisição de dados de soldagem denominado SAP $\square$ V 4.01 para a determinação dos valores de tensão e corrente de soldagem instantâneos aplicada nos ensaios através de sensores do equipamento, ou seja, valores de potência instantânea. Estas medições foram efetuadas durante toda a deposição das soldas realizando a média de todos os cordões depositados para as condições de energia de soldagem e atmosfera gasosa. O tempo de aquisição para cada cordão de solda foi de aproximadamente 30 segundos com uma taxa de aquisição de 1 segundo. A medição das energias de soldagem (ESoldagem) foi realizada utilizando a Eq. 01 levando em consideração à média e o desvio padrão dos valores de corrente de soldagem que foram dependentes da velocidade de alimentação do arame, por isso foi apresentado faixas de energias de soldagem variáveis.

$$
\text { ESoldagem }=\frac{V^{*} I}{v \text { sol }} \quad(\mathrm{J} / \mathrm{mm})
$$

A Tabela 1 apresenta composição química nominal do arame e a dureza típica do metal de solda em terceira camada, conforme indicação do fabricante. As soldas foram efetuadas utilizando um consumível arame tubular autoprotegido de liga $\mathrm{FeCrC}+\mathrm{Ti}$, com 1,6 mm de diâmetro. 
Tabela 1. Composição química e dureza nominal do consumível.

\begin{tabular}{|c|c|c|c|c|c|c|c|}
\hline \multirow{2}{*}{$\begin{array}{c}\text { Tipo de } \\
\text { arame }\end{array}$} & \multirow{2}{*}{$\begin{array}{c}\text { Dureza típica } \\
(\mathrm{HV})\end{array}$} & \multicolumn{5}{|c|}{ Composição Química (\%) } \\
\cline { 3 - 8 } & & $\mathrm{C}$ & $\mathrm{Si}$ & $\mathrm{Mn}$ & $\mathrm{Cr}$ & $\mathrm{Mo}$ & $\mathrm{Ti}$ \\
\hline FeCrC+Ti & $565\left(3^{\text {a }}\right.$ camada) & 2,0 & 0,4 & 1,0 & 6,5 & 1,1 & 6,0 \\
\hline
\end{tabular}

Com a velocidade de soldagem (Vsol), a distância entre o bico de contato à peça (DBCP) e o grau de inclinação da tocha de soldagem mantidos constantes para todas as deposições em 5 $\mathrm{mm} / \mathrm{s}, 20 \mathrm{~mm} \mathrm{e} 75^{\circ}$ positivo, respectivamente, foram depositados cordões de solda sobrepostos para formar os revestimentos com as condições descritas na Tabela 2. Nessa tabela pode-se ver que houve variação da tensão (V), corrente (I) e percentual de gás de proteção, gerando quatro condições de soldagem, que são: alta energia e sem gás de proteção (AS), baixa energia e sem gás de proteção (BS), alta energia e com gás de proteção (AC) e baixa energia e com gás de proteção $(\mathrm{BC})$. Com o intuito de avaliar o percentual de Carbono, a dureza, a microestrutura, a perda de massa e os mecanismos de desgaste foram depositados revestimentos utilizando-se as variáveis da Tabela 2, variando apenas o número de camadas. Na Tabela 3 têm-se todas as condições de aplicação dos revestimentos.

Tabela 2. Parâmetro para a aplicação dos cordões de solda.

\begin{tabular}{|c|c|c|c|c|c|}
\hline \multirow{2}{*}{$\begin{array}{c}\text { Condições } \\
\text { de } \\
\text { Soldagem }\end{array}$} & \multicolumn{4}{|c|}{ Variáveis } & \multirow{2}{*}{$\begin{array}{l}\text { Energia } \\
(\mathrm{J} / \mathrm{mm})^{*}\end{array}$} \\
\hline & $\begin{array}{c}\text { Tensão } \\
(\mathrm{V})\end{array}$ & \begin{tabular}{|l} 
Valim \\
$(\mathrm{mm} / \mathrm{s})$
\end{tabular} & $\begin{array}{c}\text { Corrente } \\
\text { (A)* }\end{array}$ & $\begin{array}{c}\text { Gás } \\
{[\% \mathrm{CO} 2]}\end{array}$ & \\
\hline AS & 28 & 117 & $262 \pm 10$ & - & $1467 \pm 56$ \\
\hline BS & 25 & 50 & $163 \pm 3$ & - & $815 \pm 15$ \\
\hline $\mathrm{AC}$ & 28 & 117 & $265 \pm 6$ & 100 & $1484 \pm 33$ \\
\hline $\mathrm{BC}$ & 25 & 50 & $165 \pm 2$ & 100 & $825 \pm 10$ \\
\hline \multicolumn{6}{|c|}{ média \pm desvio padrão } \\
\hline
\end{tabular}

Tabela 3. Esquema de deposição dos revestimentos.

\begin{tabular}{|c|c|c|c|}
\hline $\begin{array}{l}\text { Condições de } \\
\text { soldagem }\end{array}$ & Energia & $\begin{array}{c}\text { Atmosfera } \\
\text { gasosa }\end{array}$ & $\mathrm{N}^{\mathrm{o}}$ de Camadas \\
\hline $\mathrm{AC} 1$ & \multirow{3}{*}{ Alta } & \multirow{6}{*}{$\mathrm{Com} \mathrm{CO} 2$} & 1 Camada \\
\hline $\mathrm{AC2}$ & & & 2 Camadas \\
\hline $\mathrm{AC} 4$ & & & 4 Camadas \\
\hline $\mathrm{BC} 1$ & \multirow{3}{*}{ Baixa } & & 1 Camada \\
\hline $\mathrm{BC} 2$ & & & 2 Camadas \\
\hline $\mathrm{BC} 4$ & & & 4 Camadas \\
\hline AS1 & \multirow{3}{*}{ Alta } & \multirow{6}{*}{ Sem $\mathrm{CO} 2$} & 1 Camada \\
\hline AS2 & & & 2 Camadas \\
\hline AS4 & & & 4 Camadas \\
\hline BS1 & \multirow{3}{*}{ Baixa } & & 1 Camada \\
\hline BS2 & & & 2 Camadas \\
\hline BS4 & & & 4 Camadas \\
\hline
\end{tabular}

Os revestimentos foram obtidos pela deposição de camadas de cordões sobrepostos lateralmente e os corpos de prova para análise de desgaste foram retirados da região central das chapas de teste, conforme mostrado na Figura 1.

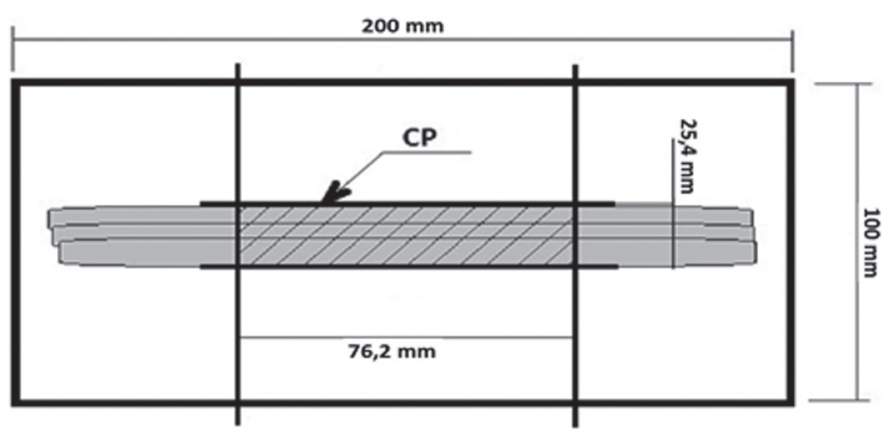

Figura 1. Representação esquemática dos cortes da amostra e deposição dos revestimentos para a análise de desgaste abrasivo.

A medição da diluição "Dil" foi realizada em cordões de solda individuais para as condições de energia de soldagem e atmosfera gasosa, efetuada através da análise de proporção das áreas de reforço "Aref" e penetração "Apen", nas imagens das seções transversais dos cordões. Neste caso foi feita a medição da área transversal de material fundido abaixo da linha horizontal do substrato, e encontrada a relação com a área transversal total do cordão solidificado. Com estas medições realizadas foi calculada a diluição da solda por meio da Eq. 2. Para isso as amostras foram cortadas, lixadas e atacadas quimicamente com nital $10 \%$ por 30 segundos para destacar os contornos do cordão, e em seguida, foram fotografadas e mensuradas utilizando o software Auto-CAD.

$$
\text { Dil }=\frac{\text { Apen }}{\text { Aref }+ \text { Apen }} \times 100 \% \quad(\%) \quad \text { Eq. } 2
$$

Para a realização da perda de massa foi utilizado um Abrasômetro Roda de Borracha simulando o desgaste abrasivo de baixa tensão, seguindo o procedimento $\square \mathrm{B} \square$ da norma ASTM G65 [18]. Nesse tipo de ensaio, utilizam-se corpos de prova com dimensões padronizadas de $76,2 \mathrm{~mm}$ de comprimento, 25,4 mm de largura e como abrasivo areia normal brasileira com granulometria \#100. Foi realizado usinagem das faces e posteriormente acabamento por retificação na face a ser desgastada. Para a determinação da perda de massa, e, consequentemente, o desgaste abrasivo, os corpos de prova foram pesados antes e após o ensaio de desgaste utilizando uma balança eletrônica com resolução de $0,1 \mathrm{mg}$.

Utilizou-se o equipamento analisador de Carbono/Enxofre, marca Horiba, para confirmar o percentual de carbono dos revestimentos e amostras de arame, foi retirada a parte inicial dos corpos de prova de cada condição de deposição dos revestimentos e efetuado a medição de dois pontos para cada 
amostra.

Para a medição do percentual de Carbono das amostras dos arames foram depositadas seis camadas de revestimentos a fim de evitar a influência do material do substrato no resultado, devido a diluição.

Utilizou-se o equipamento EMCO - TEST M4C, para a realização das medições de dureza dos revestimentos. Foram efetuadas seis medições de dureza em HV 30 durante 10 segundos. As posições das medições de dureza nos revestimentos são demonstradas na Figura 2.

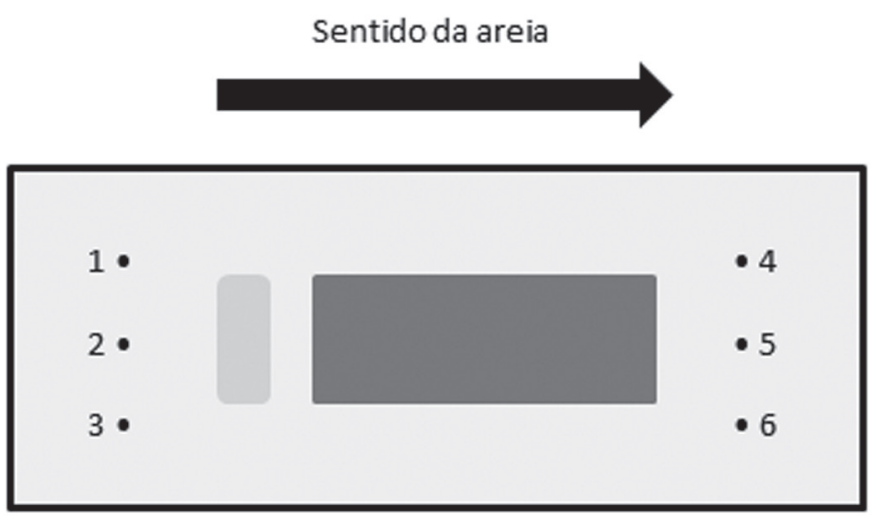

Figura 2. Esquema da posição das indentações das durezas nos revestimentos.

A preparação metalográfica foi realizada para a determinação da microestrutura. Estas amostras foram atacadas com reagente Vilella durante 1 minuto. Para obter a media da fração volumétrica dos constituintes, foram analisadas dez imagens da seção transversal a $0,2 \mathrm{~mm}$ da superfície dos revestimentos de modo a simular a região desgastada pela roda de borracha.

As imagens foram feitas através de microscopia ótica utilizando microscópio NEOPHOT 32 com aumento de 1000 vezes, e analisadas através do software "Image-Pro Plus" por medidas e contagem de objetos. Imagens por MEV (Microscopia Eletrônica de Varredura) e análise por sonda EDS (espectroscopia de energia dispersiva) foram usados para ajudar na caracterização dos microconstituintes e nos mecanismos de desgaste.

\section{Resultados e Discussão}

A Tabela 4 mostra os resultados de percentual de Carbono e carbonetos de Titânio, dureza e perda de massa dos revestimentos para todas as condições de deposição. Os valores de diluição foram medidos em cordões únicos para as condições de alta energia de soldagem sem gás, alta energia de soldagem com gás, baixa energia de soldagem sem gás e baixa energia de soldagem com gás.
Tabela 4. Resultados da caracterização dos revestimentos depositados em todas as condições de soldagem (os valores, exceto para a diluição, estão no formato média \pm desvio padrão).

\begin{tabular}{|c|c|c|c|c|c|}
\hline $\begin{array}{l}\text { Condições } \\
\text { de } \\
\text { Soldagem }\end{array}$ & $\begin{array}{c}\text { Carbono } \\
{[\%]}\end{array}$ & $\begin{array}{l}\mathrm{TiC} \\
{[\%]}\end{array}$ & $\begin{array}{c}\text { Dureza } \\
{[\mathrm{VH}]}\end{array}$ & $\begin{array}{c}\text { Perda de } \\
\text { Massa } \\
{[\mathrm{mg}]}\end{array}$ & $\begin{array}{c}\% \\
\text { Diluição } \\
{[\%]}\end{array}$ \\
\hline $\mathrm{AC} 1$ & $1,26 \pm 0,01$ & $1,98 \pm 1,0$ & $658 \pm 10$ & $221,4 \pm 11,9$ & \multirow{3}{*}{47,7} \\
\hline $\mathrm{AC} 2$ & $1,40 \pm 0,02$ & $9,82 \pm 1,5$ & $707 \pm 08$ & $139,1 \pm 5,9$ & \\
\hline AC4 & $1,52 \pm 0,01$ & $4,90 \pm 2,5$ & $695 \pm 10$ & $142,3 \pm 9,2$ & \\
\hline AS1 & $1,22 \pm 0,01$ & $3,20 \pm 1,0$ & $660 \pm 08$ & $216,2 \pm 13,1$ & \multirow{3}{*}{45,1} \\
\hline AS2 & $1,48 \pm 0,02$ & $7,10 \pm 0,5$ & $707 \pm 14$ & $137,9 \pm 5,2$ & \\
\hline AS4 & $1,38 \pm 0,02$ & $5,13 \pm 1,0$ & $675 \pm 00$ & $178,0 \pm 2,4$ & \\
\hline $\mathrm{BC} 1$ & $1,13 \pm 0,01$ & $3,28 \pm 2,0$ & $663 \pm 05$ & $234,5 \pm 5,4$ & \multirow{3}{*}{47,1} \\
\hline $\mathrm{BC} 2$ & $1,37 \pm 0,01$ & $5,22 \pm 1,0$ & $715 \pm 30$ & $169,7 \pm 10,9$ & \\
\hline $\mathrm{BC} 4$ & $1,48 \pm 0,00$ & $7,80 \pm 2,5$ & $670 \pm 25$ & $180,6 \pm 5,5$ & \\
\hline BS1 & $1,11 \pm 0,00$ & $4,36 \pm 1,0$ & $680 \pm 14$ & $205,6 \pm 4,6$ & \multirow{3}{*}{51,3} \\
\hline BS2 & $1,43 \pm 0,01$ & $7,76 \pm 2,5$ & $730 \pm 00$ & $210,7 \pm 4,7$ & \\
\hline BS4 & $1,51 \pm 0,01$ & $6,43 \pm 2,5$ & $673 \pm 22$ & $169,6 \pm 10,8$ & \\
\hline & dos ara & $\begin{array}{l}\text { "como } \\
( \pm 0,01)\end{array}$ & $\overline{\text { sitad }}$ & $1,57-1,80$ & \\
\hline
\end{tabular}

\subsection{Percentual de Carbono}

Na Tabela 4 e na Figura 3 podem ser vistos os valores do percentual de Carbono dos revestimentos depositados com todas as condições de soldagem e o desvio padrão (Dp). Além disso, têm-se também os percentuais de Carbono do arame "como depositado". É possível perceber que não houve acréscimo de Carbono na composição dos revestimentos comparado ao arame como depositado, porém nota-se que há condições que apresentaram menor perda de Carbono. Então, pode-se considerar que em nenhuma condição de aplicação de revestimento houve "acréscimo" de Carbono provido do gás aplicado, mas apenas menor perda de Carbono.

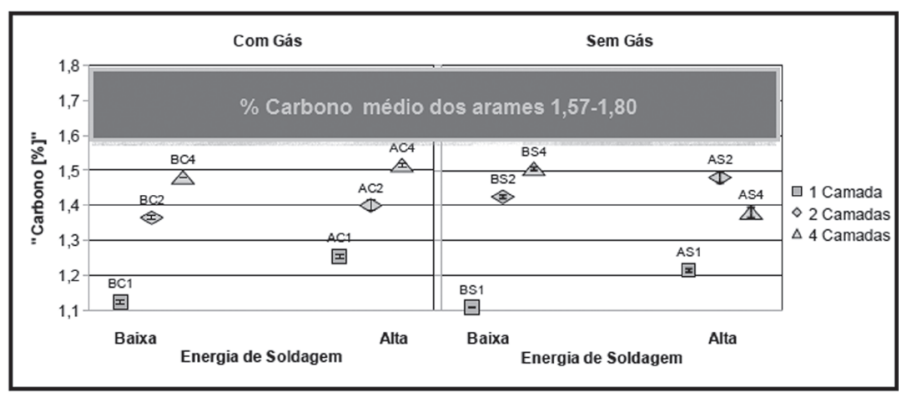

Figura 3. Percentual de Carbono nos revestimentos e nas amostras do arame.

Analisando os resultados verifica-se que a energia de soldagem influenciou no percentual de Carbono em todas as condições de deposição dos revestimentos. De uma forma geral, o aumento da energia de soldagem proporcionou menor perda de Carbono para todas as condições com exceção das amostras depositadas em quatro camadas sem adição de gás de proteção (BS4 e AS4). No presente trabalho não foi possível determinar a causa dessas alterações no teor de carbono com a variação da energia de soldagem. Com relação ao efeito do gás adicional 
de CO2 verifica-se que não houve um comportamento padrão, ou seja, os resultados do percentual de Carbono das amostras apresentaram-se não linear com a adição do CO2.

Observando os resultados pode-se dizer que a adição de camadas de revestimentos tem grande influência na composição química do material com relação ao percentual de Carbono. Pois um aumento do número de camadas minimizou a perda de Carbono dos revestimentos devido ao efeito da diluição, a partir da segunda camada obtêm-se materiais mais próximos ao arame. Foi observado um comportamento padrão entre todas as amostras depositadas com uma e duas camadas de revestimentos, onde o maior número de camadas apresentou menor perda de Carbono.

Como o material diluído, da primeira camada, apresenta características do material do revestimento e do metal de base, é de se esperar que ocorra um equilíbrio nos valores de percentual de Carbono pela diluição nas próximas camadas. Então é possível verificar que há tendência de equilíbrio com o aumento do número de camadas. Isso pode ser explicado devido ao fato de que a interação do metal de base causada pela diluição é maior nas primeiras camadas, então a perda de carbono é maior em camada única comparada com as demais camadas. Porém observa-se que há uma exceção nas mostras depositadas com alta energia sem proteção gasosa entre duas (AS2) e quatro (AS4) camadas de revestimentos.

\subsection{Dureza}

A Tabela 4 e na Figura 4 apresenta os resultados médios de Dureza HV e desvio padrão (Dp) na superfície dos revestimentos para as amostras depositadas variando as condições de energia de soldagem, gás de proteção e quantidade de camadas de revestimentos. Conforme os dados informados no catálogo do eletrodo fornecido pelo fabricante, a dureza obtida em terceira camada seria de $565 \mathrm{HV}$ “como soldado". Porém a menor dureza encontrada nestes experimentos foi de aproximadamente 658 $\mathrm{HV}$ e a maior dureza foi $730 \mathrm{HV}$, resultados semelhantes aos encontrados por LIMA e FERRARESI [19]. A dureza depende de vários fatores como velocidade de resfriamento, temperatura entre passes, preaquecimento entre outros. Então se pode dizer que é possível obter uma faixa de valores diferentes de dureza para um mesmo material.

Entretanto, se comparar a dureza de um único cordão (825 HV) dos resultados obtidos por Colaço et al. [20] com o revestimento deste trabalho é possível perceber que a dureza diminui com o tratamento térmico realizado pelo cordão subsequente na formação do revestimento. É possível verificar que o aumento da energia de soldagem e a adição do gás $\mathrm{CO} 2$ não apresentaram influência significativa na dureza dos revestimentos. É possível perceber que a dureza é menor na primeira camada dos revestimentos depositados independente da energia de soldagem e gás de proteção. Verifica-se que duas e quatro camadas apresentam dureza similar devido a menor influência da diluição entre as camadas e o metal base [16]. As amostras "AS4" apresentaram menor dureza possivelmente devido a maior perda de carbono. Se levar em consideração somente a dureza como parâmetro de redução da perda de massa, pode-se considerar desnecessária a aplicação de revestimentos com maiores quantidades de camada, pois os melhores resultados de dureza obtidos foram dos revestimentos depositados com duas camadas.

\subsection{Microestrutura}

A microestrutura do revestimento $\mathrm{FeCrC}$-Ti observada por microscopia ótica pode ser mostrada na Figura 5. A microestrutura apresenta uma matriz martensítica com austenita retida. Além disso, pode-se constatar a presença de carbonetos secundários precipitados nos contornos de grão e carbonetos primários dispersos na matriz. Vários autores como CORONADO et al. [6], LIMA e FERRARESI [19] e WANG et al. [21] também encontraram esse tipo de microestrutura nos depósitos de revestimento com materiais semelhantes de liga $\mathrm{FeCrC}-\mathrm{Ti}$ utilizada neste trabalho. Para comprovar por meio da análise química os constituintes das fases detectadas pela microscopia óptica foram feitas análises por MEV e EDS. Os constituintes mostrados na Figura 6 a por MEV foram identificados por meio de EDS como mostrada através da Figura 6b, o espectro de EDS mostra que os constituintes são formados basicamente de Carbono e Titânio, ou seja, são provavelmente carbonetos de Titânio. É possível identificar carbonetos de Titânio ancorados

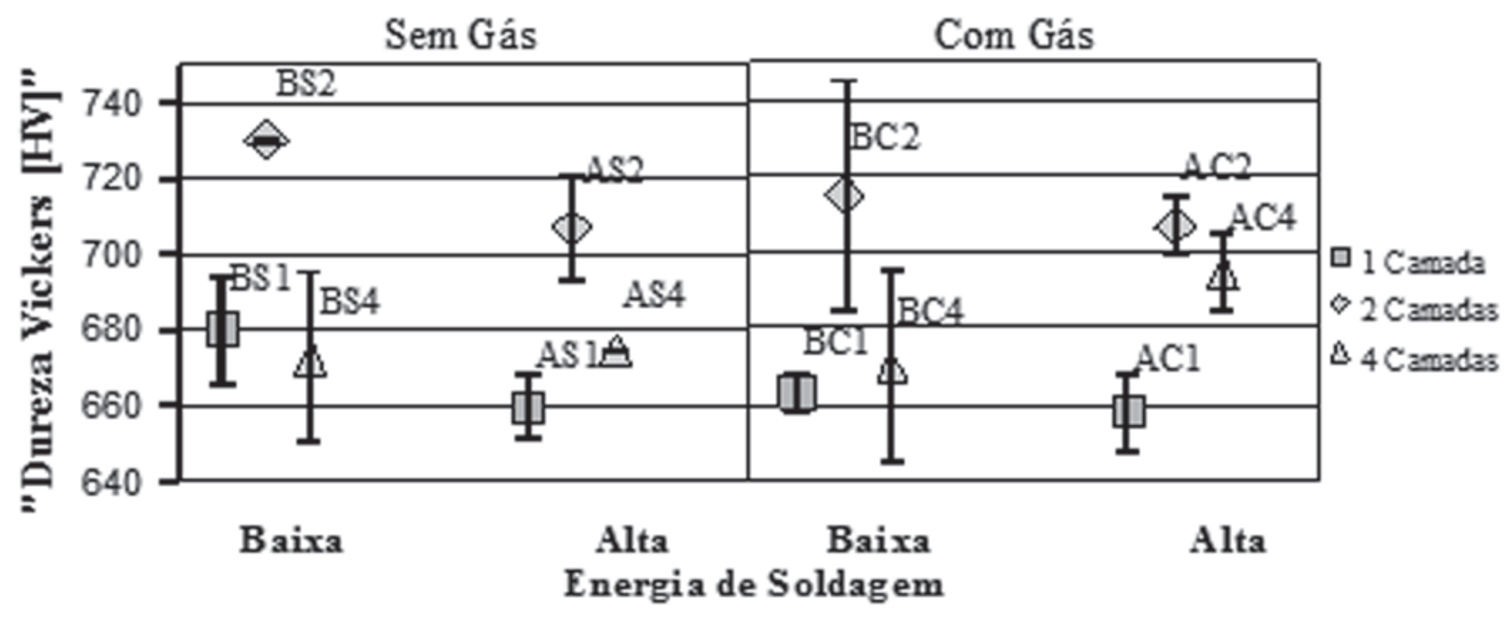

Figura 4. Dureza das amostras dos revestimentos. 
em matriz martensítica e regiões de austenita retida assim com na microestrutura encontrada por CORONADO et al. [6], LIMA e FERRARESI [19] e WANG et al. [21].

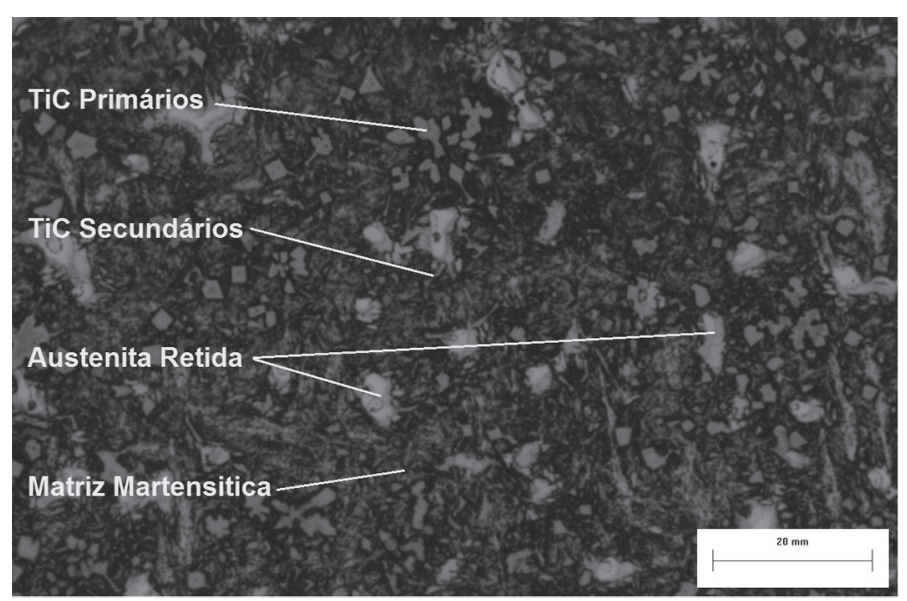

Figura 5. Microestrutura dos revestimentos mostrados por microscopia ótica.

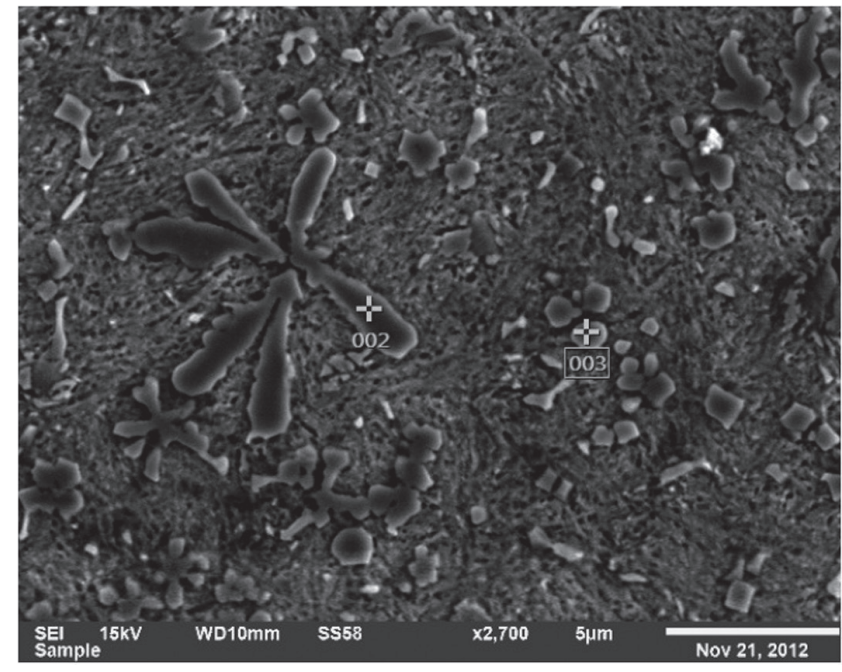

\subsection{Percentual de Carbonetos de Titânio}

Através daanálise dos resultados da Tabela4eFigura 7verificase que a energia de soldagem influenciou significativamente no percentual de carbonetos na segunda e na quarta camada dos revestimentos depositados somente com proteção gasosa de $\mathrm{CO} 2$. Observando o aumento da energia de soldagem sem gás de proteção, os resultados de percentual de carbonetos de Titânio não apresentaram diferenças significativas. Entretanto, o gás de proteção de $\mathrm{CO} 2$ não influenciou significativamente no percentual de carbonetos de Titânio, com exceção das amostras depositadas na segunda camada com alta energia de soldagem.

Com relação ao número de camadas, observaram-se os maiores percentuais de carbonetos de Titânio nos depósitos em segunda camada com exceção dos revestimentos depositados com baixa energia e com proteção gasosa de CO2 (BC2). Notase uma diferença considerável entre as primeiras camadas de revestimentos com relação às camadas duplas, principalmente quando se utilizou proteção gasosa de $\mathrm{CO} 2$, onde os revestimentos apresentaram um aumento de aproximadamente 7,8\% com a adição da segunda camada, para as outras condições essa
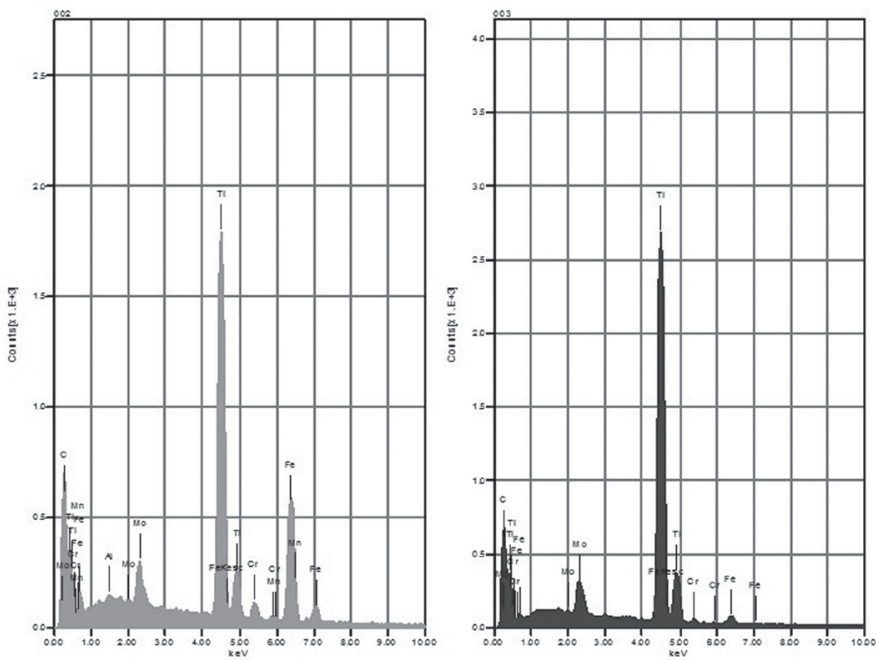

Figura 6. Microestrutura dos revestimentos mostrados por a) MEV e b) EDS.

ComGás

SemGás

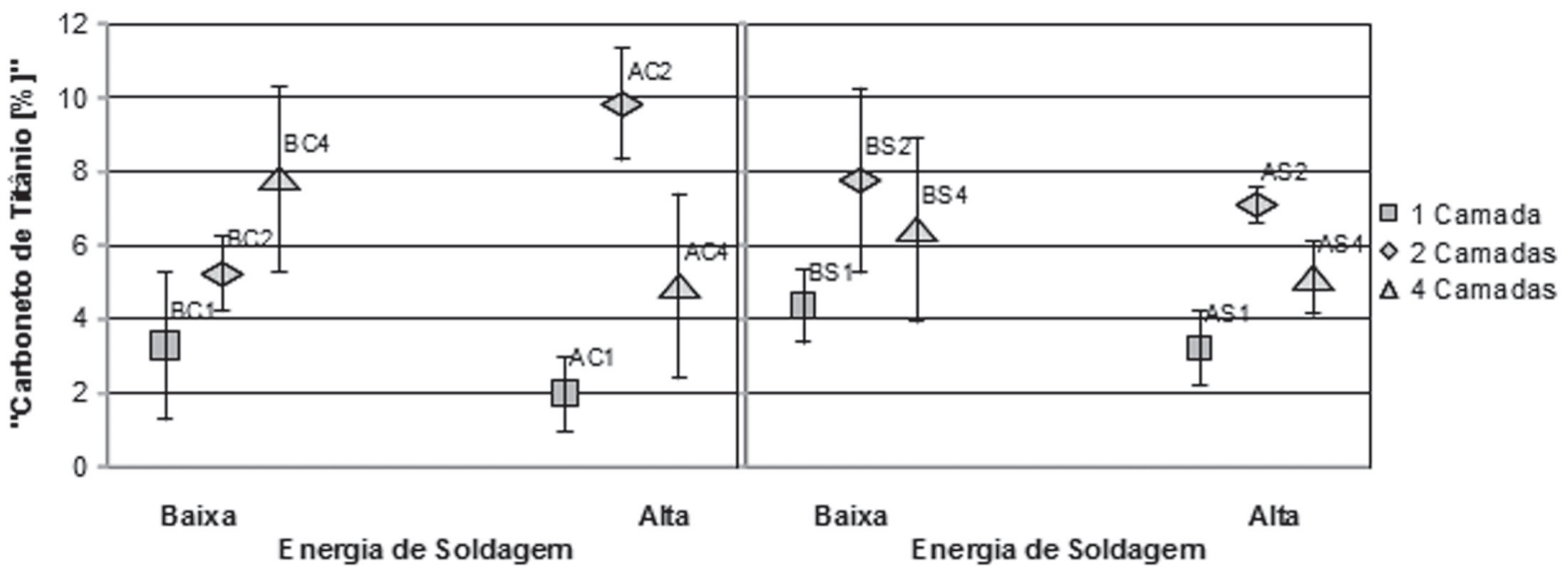

Figura 7. Valores de percentual de carbonetos de Titânio. 
diferença foi de 2 a $4 \%$ para mais na quantidade de carbonetos. O comportamento apresentado de aumento na quantidade de carbonetos em duas e quatro camadas em relação à camada única acontece devido ao efeito da diluição, pois o metal de base contém um percentual de Carbono baixo diluindo Carbono da primeira camada do revestimento. Porém não foi possível determinar a causa do aumento na quantidade de carbonetos quando se tem duas camadas em relação a quatro camadas.

Assim como CORONADO et al. [6], a fração volumétrica de carbonetos apresentou um aumento entre a primeira camada e as demais devido o efeito da diluição, porém estes autores produziram revestimentos com maior percentual de carbonetos. Então se pode perceber que há uma ligação entre o efeito da diluição através do número de camadas com a menor perda de Carbono, consequentemente afetando o percentual de carbonetos de Titânio e melhorando a resistência ao desgaste abrasivo.

\subsection{Perda de Massa}

A Figura 8 mostra valores médios de perda de massa em função da energia de soldagem com e sem atmosfera gasosa de $\mathrm{CO} 2$ para revestimento com uma, duas e quatro camadas. nos cordões formando diferentes microestruturas.

Mesmo que as amostras BC2 e AC2 apresentaram valores próximos de percentual de Carbono, as amostras depositadas com alta energia de soldagem com proteção gasosa obtiveram maior formação de carbonetos de Titânio. Porém apresentaram os mesmos valores de dureza que confirmam os relatos de RIBEIRO [22] e KOTECKI e OGBOM [23], onde concluíram que a dureza não é o único fator indicativo da resistência ao desgaste, mas também a microestrutura através da quantidade de carbonetos nos revestimentos. Da mesma forma o comportamento das amostras depositadas em quarta camada com gás mostram o efeito da energia de soldagem na perda de massa. Nota-se que as amostras de alta energia (AC4) apresentaram maior percentual de Carbono com relação às amostras de baixa energia (BC4). Neste caso o comportamento da quantidade de Carbono não foi a mesma, pois um menor teor de Carbono propiciou um aumento no teor de carboneto de Titânio em torno de 3\% para as amostras baixa energia (BC4), que por sua vez refletiu na tendência de aumento na dureza com o aumento da energia de soldagem.

Segundo CORONADO et al. [6], ZUM GAHR [11] e HUTCHINGS [24] o aumento da fração volumétrica dos carbonetos de Titânio minimizam os efeitos da perda de massa

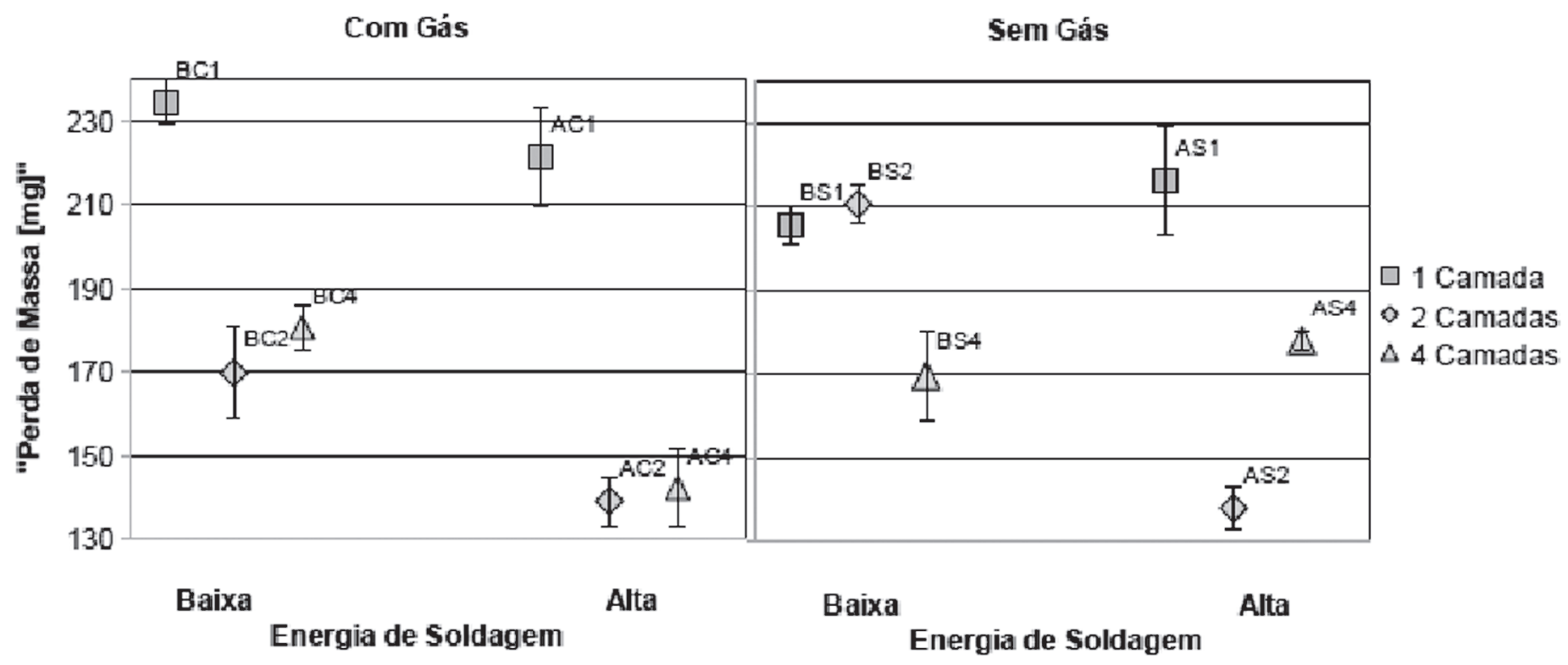

Figura 8. Valores de perda de massa dos revestimentos.

É possível verificar que o efeito da energia de soldagem na perda de massa dos revestimentos teve comportamentos diferentes com a variação do número de camadas e gás de proteção. De um modo geral os revestimentos aplicados com alta energia de soldagem apresentaram menor ou igual perda de massa em relação àqueles aplicados com baixa energia. Para todos os revestimentos com uma camada e para aqueles com 4 camadas sem gás de proteção $\mathrm{CO} 2$ não houve influência da energia de soldagem, pois os valores de perda de massa não apresentaram diferenças significativas. Nos demais casos os revestimentos apresentaram menor perda de massa quando aplicados com maior energia, devido à influência da velocidade de resfriamento nos revestimentos. Porém mesmo com a vantagem da maior quantidade de carbonetos em relação à amostra $\mathrm{AC} 4$, a perda de massa foi maior para as amostras de baixa energia com proteção gasosa (BC4) devido à presença de trincas gerada pela alta taxa de resfriamento. No caso da perda de massa dos revestimentos depositados na segunda camada sem atmosfera gasosa, o efeito da energia de soldagem foi basicamente na velocidade de resfriamento. Visto que com o aumento da energia de soldagem houve um pequeno aumento de $0,6 \%$ na quantidade dos carbonetos, porém o revestimento foi fragilizado pelas trincas causadas pela maior taxa de resfriamento no revestimento depositado com baixa energia de soldagem (BS2). 
É possível verificar também o efeito do gás de proteção adicional nas condições de deposição dos revestimentos. Avaliando os dados é possível perceber dois comportamentos diferentes com relação a influência da proteção gasosa na perda de massa. O primeiro comportamento foi observado em alta energia de soldagem onde o gás de proteção não influencia a perda de massa, exceto para a condição de soldagem com quatro camadas onde houve maior perda de massa com a aplicação do revestimento sem gás de proteção $(\mathrm{AC} 4<\mathrm{AS} 4)$. Esse comportamento pode estar associado ao maior percentual de Carbono, e consequentemente maior quantidade de carbonetos, que as amostras depositadas com gás de proteção $\mathrm{CO} 2$ apresentaram e também pela presença de trincas nas amostras AS4 onde pode reduzir a resistência ao desgaste abrasivo. Com baixa energia não houve comportamento similar, pois se percebeu que para baixa energia de soldagem a proteção gasosa influenciou significativamente na perda de massa. As amostras depositadas em camada única com proteção gasosa (BC1) apresentaram perda de massa $12,3 \%$ maior em relação às deposições sem gás (BS1). De outra maneira, a perda de massa das amostras depositadas em segunda camada com proteção gasosa $(\mathrm{BC} 2)$ resultou em 19,5\% menor em relação às deposições sem gás de proteção (BS2). Esse comportamento apresentado pelas amostras depositadas em segunda camada é justificado através da maior presença de trincas nas amostras BS2 mesmo apresentando maior concentração de carbonetos de Titânio.

Fazendo uma análise com relação à quantidade de camadas de revestimentos. Verifica-se que o número de camadas foi influente quando se compara revestimentos com uma camada e revestimentos com duas e quatro camadas, ou seja, a partir de revestimentos aplicados com duas camadas não houve alteração da perda de massa, exceto nos revestimentos aplicados com baixa energia de soldagem e sem gás de proteção (BS1, BS2 e BS4) onde houve presença significativa de trincas. A maior variação ocorreu nas amostras depositadas com alta energia e com atmosfera gasosa de $\mathrm{CO} 2(\mathrm{AC} 1>\mathrm{AC} 2)$ onde a perda de massa foi $37 \%$ menor nas amostras depositadas em segunda camada (AC2) em relação às amostras com camada única (AC1). Assim como as amostras de alta energia sem a proteção gasosa de $\mathrm{CO} 2$ apresentaram 36\% menor perda de massa em duas camadas (AS2) quando comparado aos revestimentos com uma camada (AS1).

Da mesma maneira, os revestimentos aplicados com baixa energia foram $27,6 \%$ menor com a adição da segunda camada de revestimento e gás de proteção. Sem a proteção gasosa a perda de massa foi dependente da quantidade de trincas presentes na área de desgaste do revestimento. Esse comportamento de redução da perda de massa com o aumento do número de camadas é consequente da redução do efeito da diluição, que por sua vez tem uma relação com a composição química e por consequência com a microestrutura final do revestimento [22]. Quando se verifica o percentual de diluição na primeira camada com aproximadamente $50 \%$ em média, nas camadas posteriores, em teoria, tem-se aproximadamente $25 \%$ da composição do metal de base, então se justifica a melhora nas características dos revestimentos acima de duas camadas através da diluição.
A diluição também influencia sobre a quantidade de carbonetos resultando em variações na dureza do revestimento, como se pode observar entre a primeira e segunda camadas dos revestimentos. Na segunda camada onde o efeito da diluição foi menor, houve um aumento no percentual de carbono, que por consequência proporcionou maiores valores de percentual de carbonetos e dureza, com isso melhorando a resistência ao desgaste abrasivo.

O número de camadas dos revestimentos foi determinante na perda de massa dos revestimentos. Revestimentos aplicados com apenas uma camada apresentaram maior perda de massa em relação àqueles com duas e quatro camadas, independente da energia e percentual de $\mathrm{CO} 2$. Revestimentos com uma camada apresentaram menor percentual de carbonetos de Titânio devido ao efeito da diluição do metal de base.

Dessa maneira esses revestimentos apresentaram menor resistência ao desgaste que pode ser associado a presença de carbonetos de Titânio. Resultados obtidos por CORONADO et al. [6] mostraram que a adição da terceira camada de revestimento melhorou em mais de $35 \%$ na perda de massa com relação a primeira camada em revestimentos semelhantes aos utilizados neste trabalho contendo teor de Titânio na composição do material. SEVILLA et al. [25] observaram melhora na resistência ao desgaste com a adição da segunda camada de revestimento. Assim como trabalhos de RIBEIRO [22] onde percebeu uma redução na perda de massa com a adição da segunda camada, além de observar que a resistência ao desgaste em camada única é mais prejudicada aumentando a energia de soldagem.

Em outras palavras, com a adição da segunda camada de revestimento o comportamento da perda de massa é diminuído devido ao efeito da diluição do arame-eletrodo acontecer em materiais com composição mais próxima do próprio material de adição, ou seja, estará depositando cordões sobre o revestimento com material muito próximo do original e não mais sobre um material com propriedades muito diferentes. Sendo assim adquirindo as qualidades desejadas. Porém há exceções, pois fatores como a velocidade de resfriamento afetam a perda de massa devido à formação de trincas.

\subsection{Mecanismos de desgaste}

As micrografias obtidas por MEV da superfície desgastadas dos revestimentos da liga $\mathrm{FeCrC}-\mathrm{Ti}$ mostradas na Figura 9a revelam que o principal mecanismo de desgaste é o microriscamento. Pode-se observar a influência dos carbonetos de Titânio no fenômeno de microriscamento e, por consequência, na perda de massa. Verifica-se que nos carbonetos de Titânio pequenos o risco provocado pelo abrasivo não é interrompido (Figura 9a indicação "A"). Por outro lado carbonetos de tamanho maior funcionam como barreira para o abrasivo provocar o microriscamento (Figura 9a indicação "B"). Na análise das superfícies desgastadas dos revestimentos verifica-se que o abrasivo gera riscos na matriz. Por outro lado o risco gerado pelo abrasivo é interrompido devido ao contato com o carboneto. Em casos onde o abrasivo é maior que o carboneto, a deformação causada não é afetada pela presença do carboneto.

Através da Figura 9a podem-se constatar os resultados de 

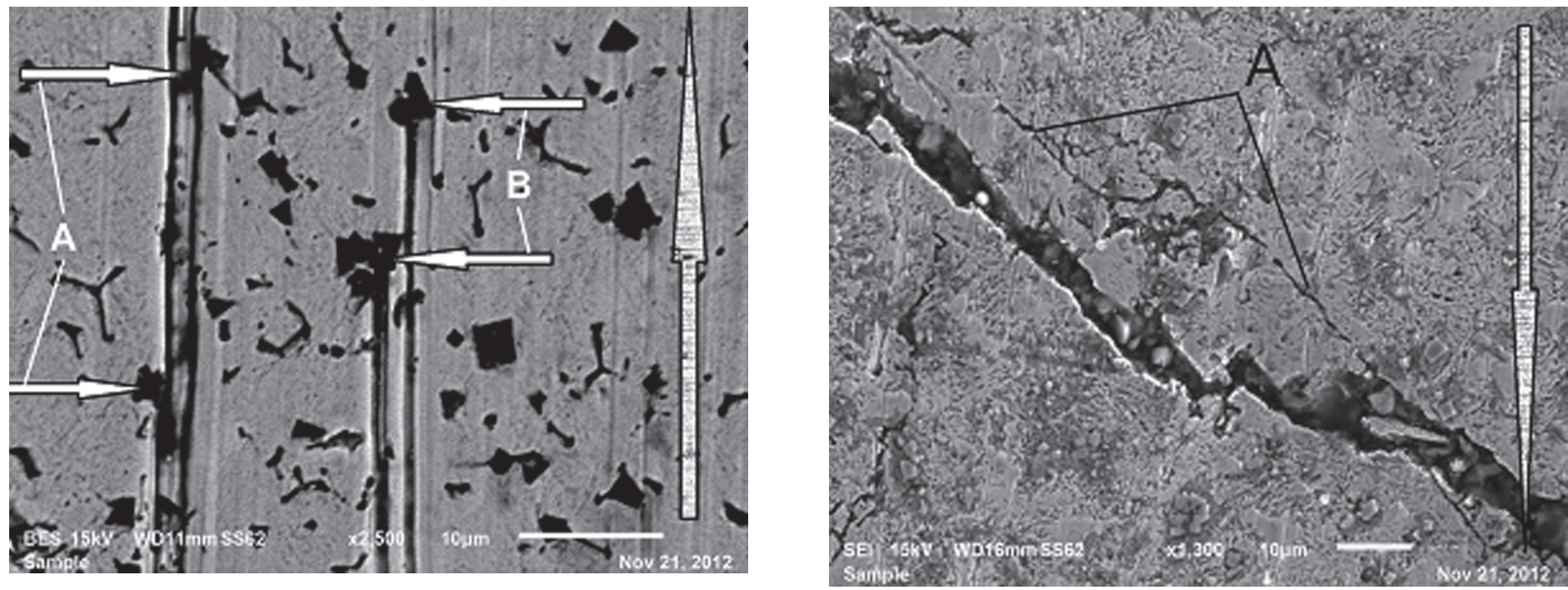

Figura 9. Mecanismo de desgaste da superfície dos revestimentos mostrado através do MEV.

ALBERTIN e SINATORA [26] onde o risco do abrasivo é barrado pelo carboneto de tamanho maior, esse comportamento ocorreu devido a resistência da matriz em ancorar os carbonetos. Outro mecanismo envolvido na perda de massa é o arrancamento de material entre as trincas existentes no revestimento. $\mathrm{Na}$ Figura 9b é possível verificar uma trinca decorrente do processo de resfriamento durante a soldagem do revestimento e uma trinca paralela com tamanho e largura menor (na indicação "A") possivelmente causada pela passagem do abrasivo. Com essa trinca paralela, o revestimento fica mais suscetível ao arrancamento de material da região entre as trincas devido à passagem das partículas abrasivas, que é comprovado pelos riscos no revestimento, caracterizado como um dos mecanismos de desgaste.

A resistência ao desgaste abrasivo pode ser diminuída com a presença de trincas na superfície dos revestimentos. É possível verificar que a maioria dos revestimentos depositados com baixa energia de soldagem apresentaram trincas e foram as amostras menos resistentes ao desgaste abrasivo provocado pela roda de borracha, ou seja, apresentaram os piores resultados de perda de massa. As trincas foram fatores de redução na resistência ao desgaste abrasivo [6]. As trincas apareceram principalmente nas amostras depositadas com baixa energia de soldagem. $\mathrm{O}$ principal motivo para ocorrer esse fenômeno pode ser a alta taxa de resfriamento, justificando a maior perda de massa destes revestimentos.

De acordo com a classificação do desgaste abrasivo proposto por GATES [27], considerando o tamanho e a geometria das partículas abrasivas, a restrição ao movimento, a tensão de contato e o mecanismo dominante; o modo de desgaste apresentado nestes experimentos pode ser considerado como abrasão por baixa tensão Se observar que o valor usual para a razão entre a dureza da superfície do revestimento e a dureza do abrasivo $\mathrm{H} / \mathrm{Ha}$ de 0,8 reportado pela literatura [24,28] como limite para transição entre o regime de desgaste moderado para severo. Então observando a dureza dos revestimentos, em media $665 \mathrm{HV}$, e a do abrasivo utilizado é confirmado o modo de desgaste severo. Além dos valores de coeficiente de atrito apresentarem resultados superiores a 0,59 durante os ensaios de perda de massa indicam desgaste severo, assim como os resultados encontrados por PINTAUDE et al. [29] onde o coeficiente de atrito apresentou uma relação de transição entre desgaste moderado e severo com valor de 0,5 (coeficiente de atrito).

Então, os principais mecanismos de desgaste encontrados nestes experimentos foram o microriscamento na matriz com bloqueios na trilha de desgaste pelos carbonetos e as trincas geradas pelas maiores taxas de resfriamento das amostras de baixa energia de soldagem. O maior diferencial na perda de massa dos revestimentos foi a diluição das primeiras camadas, pois influenciaram nas características da microestrutura reduzindo a resistência ao desgaste abrasivo devido aos menores percentuais de carbonetos de Titânio. Além da taxa de resfriamento, que já citadas, foram responsáveis pelo aparecimento de trincas aumentando a perda de massa dos revestimentos.

\section{Conclusões}

Os experimentos realizados nesse trabalho permitiram concluir que:

A energia de soldagem influenciou significativamente a perda de massa dos revestimentos. Todos os revestimentos aplicados com maior energia apresentaram menor ou igual perda de massa independente do número de camadas e gás de proteção. Esse comportamento está associado à presença de trincas nos revestimentos aplicados com menor energia.

A proteção com $\mathrm{CO} 2$ não teve influência preponderante na perda de massa dos revestimentos. As diferenças detectadas são provenientes dos diferentes mecanismos de desgaste atuantes. Pois nos revestimentos aplicados com maior energia, onde não foram detectadas trincas, os valores de perda de massa são iguais. Por outro lado, naqueles aplicados com menor energia as diferenças de perda de massa devido à proteção com $\mathrm{CO} 2$ são sombreados pela grande presença de trincas nos revestimentos. 
O número de camadas dos revestimentos foi determinante na perda de massa dos revestimentos. Revestimentos aplicados com apenas uma camada apresentaram maior perda de massa em relação àqueles com duas e quatro camadas, independente da energia e do CO2. Revestimentos com uma camada apresentaram menor percentual de carbonetos de Titânio devido ao maior efeito da diluição. Dessa maneira esses revestimentos apresentaram menor resistência ao desgaste que é associado à presença de carbonetos de Titânio. Nos revestimentos com duas e quatro camadas não são encontradas diferenças na perda de massa, na dureza e no percentual de carbonetos de Titânio.

Dessa maneira conclui-se que é possível obter o mesmo desempenho em revestimentos aplicados com duas e quatro camadas. Os mecanismos de desgaste atuantes nos revestimentos são microriscamento associado com o destacamento de material fragilizado paralelo as trincas. Os carbonetos de Titânio foram preponderantes para a inibição da perda de massa dos revestimentos, principalmente aqueles com tamanhos suficientes para barrar a passagem das partículas abrasivas. A presença de trincas nos revestimentos é associada a maior perda de massa dos revestimentos.

\section{Agradecimentos}

Os autores expressam o seu agradecimento à Universidade Tecnológica Federal do Paraná, ao Instituto Federal de Santa Catarina, às indústrias ESAB/SA, ao Instituto de Pesquisas Tecnológicas e a Fundação Araucária.

\section{Referências Bibliográficas}

[1] MILLER, B. Frequently Asked Questions about Hardfacing, The Fabricator, 2005.

[2] BAPTISTA, A.L.B.; NASCIMENTO, I.A. Revestimentos Duros Resistentes ao Desgaste Depositados por Soldagem Utilizados na Recuperação de Elementos de Máquinas. Spectru Instrumental Científico, 2009.

[3] CHAMBERLAIN, S. Combating Tools Wear with Coating, The Fabricator, 2003.

[4] D'OLIVEIRA, A.S.C.M.; VILAR, R.; FEDER, C.G. Feder High Temperature Behaviour of Plasma Transferred Arc and Laser Co-based Alloy Coatings. Applied Surface Science. v. 201, p.154-160, 2002.

[5] WAINER, E.; BRANDI, S.; MELLO, F. Soldagem Processos e Metalurgia. Ed. Edgard Blucher. 494p. 1992.

[6] CORONADO, J.J.; CAICEDO, H.F.; GOMEZ, A.L. The effects of welding processes on abrasive wear resistance for hardfacing deposits. Tribology International, v. 42, p 745 - 749, 2009.

[7] KANNAN, T.; MURUGAN, N. Effect of Flux Cored Arc Welding Process Parameters on Duplex Stainless Steel Clad Quality. Journal of Materials Processing Technology. v. 176, p $230-239,2006$.

[8] LIMA, A.C.; FERRARESI, V.A. Análise da Resistência ao Desgaste de Revestimento Duro Aplicado por Soldagem em Facas Picadoras de Cana-de-açúcar. Soldagem \& Inspeção, v 15 (2), p 094-102 - 74, Abr/Jun 2010.
[9] BUCHELY, M. F.et al., The Effect of Microstructure on Abrasive Wear of Hardfacing Alloys. Wear. Vol. 259, p. 52-61. 2005.

[10] TYLCZAK, J. H.; ORENGON, A. Abrasive wear. In: ASM Handbook. Friction, Lubrication and Wear Technology, v.18. p.337-351, 1992.

[11] ZUM GAHR, K. H. Microstructure and Wear of Materials. Tribology Series, v. 10, Elsevier, Science Publishers, Amsterdam. 560 p. 1987.

[12] WU, H. Q. et al., Solidification of Multi- Alloyed White Cast Iron: Type and Morphology of Carbides. Transactions AFS, v. 140, p. 103-108, 1996.

[13] BOCCALINI, M.Jr.; GOLDENSTEIN, H. Solidification of High Speed Steels. International Materials Review, n.2, v. 46, p. 92-115, 2001.

[14] MARQUES, P.V.; MODENESI, P.J.; BRACARENSE, A.Q. Soldagem: Fundamentos e Tecnologia. Belo Horizonte, Ed UFMG. 363p. 2005.

[15] MACHADO, I. G. Soldagem \& Técnicas Conexas: Processos. Editado pelo autor. 477 p. 1996.

[16] RIBEIRO, R.; VENTRELLA, V.A.; GALLEGO, J.; Avaliação da Resistência ao Desgaste Abrasivo de Revestimentos Soldados do Tipo Fe-C-Cr Utilizados na Indústria Sucro Alcooleira. $60^{\circ}$ Congresso Anual da Associação Brasileira de Metalurgia e Materiais . Belo Horizonte-MG, Julho, 2005.

[17] CARDOSO, R.L. et al., Avaliação da Influencia de Gases Proteção Contendo Diferentes Teores de CO2 nas Características dos Revestimentos Soldados Visando o Reparo de Turbinas Erodidas por Cavitação Soldagem \& Inspeção, v 8 (2), p 68 - 74 , Jun 2003.

[18] ASTM. Test Method for Meassuring Abbrasion Using the Dry Sand/Rubber Wheel Apparatus. G65-00e1 Annual Book of Standards Volume 03.02: Wear and Erosion; Metal Corrosion. Philadelphia, USA, 2001.

[19] LIMA, A.C.; FERRARESI, V.A. Analise da Microestrutura e da Resistência ao Desgaste de Revestimento Duro Aplicado utilizado pela indústria Sucroalcooleira. Soldagem \& Inspeção, v 14 (2), p 140-150, Abr/Jun 2009.

[20] COLAÇO, F.H.G. et al., Influência da Energia de Soldagem no Desgaste Abrasivo de Revestimentos Duros Aplicados pelo Processo FCAW. VII Congresso Nacional de Engenharia Mecânica, Maranhão, 2012.

[21] WANG, X. H. et al., Microstructure and Wear Properties of Fe-Based Hardfacing Coating Reinforced BY TiC Particles. Journal of Materials Processing Technology. v.168, p. 89-94, 2005.

[22] RIBEIRO, R. Avaliação da Resistência ao Desgaste Abrasivo de Revestimentos Soldados do Tipo Fe-C- Cr Utilizados na Indústria Sucroalcooleira. 2004. 104p. Dissertação (Mestrado) - Universidade Estadual Paulista, Faculdade de Engenharia de Ilha Solteira. 2004.

[23] KOTECKI J, OGBOM J.S. Abrasion Resistance of Iron Based Hardfacing Alloys. Welding Journal, 1995, 74(8): 269 278.

[24] HUTCHINGS, I.M. Tribology. Friction and Wear of Engineering Materials. London: Edward Arnold, p. 273, 1992.

[25] SEVILLA, L.M.L.; PINEDA, J.C.G.; TORO, A. Relacion 
Microestructura Resistencia al Desgaste de Recubrimientos Duros Ricos en Cromo y Tungsteno Aplicados por Soldadura Electrica (SMAW). Dyna, ano/vol. 71, n.144, p.165-171, 2004.

[26] ALBERTIN E.; SINATORA A. Effect of Carbide Fraction and Matrix Microstructure on the Wear of Cast Iron Balls Tested in a Laboratory Ball Mill. Wear. v. 250, p. 492-501, 2001.

[27] GATES, J. Two-Body and Three-Body Abrasion: A Critical Discussion. Wear, v.214, n.1, p.139-146, 1998.

[28] RICHARDSON, R.C.D. The Wear of Metals by Relatively Soft Abrasive. Wear. v. 11, p. 245-275, 1968.

[29] PINTAUDE G. et al. Mild and Severe Wear of Steels and Cast Irons in Sliding Abrasion. Wear. v. 267, p.19-25, 2009. 